\title{
CLINICAL NUTRITIONAL SURVEYS
}

\section{RELATIONSHIP BETWEEN OBSERVED SIGNS}

\author{
By E. W. ADCOCK, W. H. HAMMOND AND H. E. MAGEE
}

The Ministry of Health clinical team which has been carrying out surveys into the state of nutrition of samples of the population throughout England and Wales since 1942 grouped the subjects examined into three grades, 'good', 'fair' and 'poor', and also recorded the presence of a number of conditions, twenty-nine in all (for brevity 'clinical signs') which were mentioned in the first report of the surveys (Magee, 1944). In making their evaluation of nutritional status the clinicians took account of a number of criteria-posture, tone of muscles, elasticity of skin, expression, etc. (for brevity 'grading criteria')-which were not recorded as such and are not included in the twenty-nine clinical signs mentioned above. The clinical signs recorded, i.e. folliculosis, gingivitis, corneal vascularization, etc., were not consciously taken into account in placing the subject in a nutritional grade, but were recorded independently. In view of these circumstances it was obviously desirable as soon as sufficient data became available to ascertain whether any statistical relationship existed between the grade of nutrition and the incidence of the nutritional signs.

The results of 6677 examinations, 3351 on school children aged 8-15 years and 3326 on adults, mostly factory workers, have now become available for analysis. * The incidence of folliculosis, gingivitis, corneal vascularization, pityriasis, cheilosis, angular stomatitis and enlargement of the tongue papillae, was sufficiently high to justify statistical analysis; the incidence of the remaining twenty-two clinical signs was too low. Tetrachoric correlations between the clinical signs and nutrition gradef are shown in

* For purposes of the present calculation, grades 'fair' and 'poor' were combined.

$\dagger$ The application of factor analysis to tetrachoric correlations is a statistical procedure which requires further consideration. In the present state of knowledge it is not possible to assign limits of sampling error to the results, although in our present instance the samples are so large that we do not think the conclusions would be materially affected. Furthermore, the estimation of correlations by the tetrachoric method is based on the assumption that the distributions are normal, again a point which in general requires consideration, although in biological material the assumption can often be reasonably made.

J. Hygiene 45
Table 1. A positive relation indicates clinical signs present in those rated 'poor', or absent in those classed 'good'. The correlations shown in the table are so low for most of the clinical signs that there appears little indication that the sign in question will be found more frequently in those assessed 'poor' than in those who have 'good' nutrition, so that if we take the clinical assessment as a standard the clinical signs are of no value as an indication of that assessment. The correlation between the sum of all the signs and the nutritional assessment is only 0.32 in children and 0.12 in adults. Moreover, it should be remembered that those signs which have a very low incidence can only supply positive information in a very small proportion of the population examined. For instance, cheilosis and angular stomatitis only occurred in about $2 \%$ of the population examined, and although when present they are frequently associated with poor nutritional state, their occurrence is so rare as to make them of little value for practical purposes.

The assumption adopted for the above analysis is that the assessment of nutritional grade is sufficiently correct to justify comparisons. Thus whereas the foregoing analysis uses the clinician's nutritional grading as the criterion against which to test the different signs, the next analysis ignores nutritional grade and sets out the ascertained relationship between the clinical signs singly and collectively. In other words, the criterion against which the signs are now correlated is not an external one but an internal factor (the general nutritional factor) responsible for the signs. (As an analogy we may take the case in mental testing where different intellectual tests might be correlated with an outside criterion, the teachers' estimate, or with an internal criterion, general intelligence (' $g$ '), which is responsible for the test performances themselves.) If all the signs are the clinical expression of a state of disordered nutrition, then the analysis should show positive correlation between the signs singly and collectively and, in this event, the conclusion would be inescapable that the presence or absence of these signs would have to be deliberately taken into account in assessing the nutritional state.

The inter-correlations calculated separately for children and adults are given in Table $2 \mathbf{A}, \mathbf{B}$. 
The saturation coefficients in the last line indicate the extent to which any one sign agrees with the results which would be obtained from a pool of the rest, in the same way that a correlation coefficient indicates agreement between two variables. The mode of application of factor analysis to nutritional assessment is set out in the paper by Hammond (1944). The level of the tetrachoric correlations and of the saturation coefficients is very low, and it cannot therefore be inferred that the presence of these signs is a dependable expression of the general state of nutrition.
Subnormal muscular development.

Diminished muscle tone.

Poor muscular co-ordination.

Subnormal hand grip.

Diminished subcutaneous fat.

Excess subcutaneous fat.

Skin pallor.

Skin loss of elasticity.

Abnormal pigmentation of the skin.

Lesions present in the skin.

Abnormal hair.

Pallor of mucous membranes.

Table 1. Correlation between clinical signs and nutritional grade

\begin{tabular}{|c|c|c|c|c|c|c|c|}
\hline & Pityriasis & Folliculosis & Cheilosis & $\begin{array}{l}\text { Angular } \\
\text { stomatitis }\end{array}$ & $\begin{array}{l}\text { Enlargement } \\
\text { of tongue } \\
\text { papillae }\end{array}$ & Gingivitis & $\begin{array}{c}\text { Corneal } \\
\text { vasculari } \\
\text { zation }\end{array}$ \\
\hline & 0.02 & 0.09 & 0.41 & 0.51 & 0.05 & $0 \cdot 33$ & $-0 \cdot 13$ \\
\hline dults & $0 \cdot 11$ & -0.09 & 0.21 & $-0 \cdot 17$ & $-0 \cdot 12$ & $0 \cdot 09$ & $0 \cdot 30$ \\
\hline
\end{tabular}

Table 2. Correlations between nutritional signs

\begin{tabular}{|c|c|c|c|c|c|c|c|}
\hline . & Pityriasis & Folliculosis & Cheilosis & $\begin{array}{c}\text { Angular } \\
\text { stomatitis }\end{array}$ & $\begin{array}{c}\text { Enlargemen } \\
\text { of tongue } \\
\text { papillae }\end{array}$ & Gingivitis & $\begin{array}{r}\text { Cornea } \\
\text { vascula } \\
\text { zation }\end{array}$ \\
\hline \multicolumn{8}{|c|}{ A. Children $(N=3351)$} \\
\hline Pityriasis & - & $0 \cdot 03$ & $0 \cdot 26$ & $0 \cdot 26$ & $0 \cdot 09$ & 0.08 & $0 \cdot 10$ \\
\hline Folliculosis & $0 \cdot 03$ & - & $0 \cdot 29$ & $0 \cdot 30$ & 0.00 & 0.07 & -0.12 \\
\hline Cheilosis & $0 \cdot 26$ & $0 \cdot 29$ & - & $0 \cdot 70$ & 0.55 & $0 \cdot 36$ & 0.02 \\
\hline Angular stomatitis & $0 \cdot 26$ & $0 \cdot 30$ & $0 \cdot 70$ & - & $0 \cdot 29$ & $0 \cdot 38$ & $0 \cdot 47$ \\
\hline Enlarged tongue papillae & 0.09 & $0 \cdot 00$ & 0.55 & $0 \cdot 29$ & - & $0 \cdot 09$ & $0 \cdot 14$ \\
\hline Gingivitis & $0 \cdot 08$ & $0 \cdot 07$ & $0 \cdot 36$ & $0 \cdot 38$ & $0 \cdot 09$ & - & $0 \cdot 13$ \\
\hline Corneal vascularization & $0 \cdot 10$ & $-0 \cdot 12$ & 0.02 & $0 \cdot 47$ & $0 \cdot 14$ & $0 \cdot 13$ & - \\
\hline General factor saturation & $0 \cdot 27$ & $0 \cdot 18$ & $0 \cdot 86$ & 0.99 & $0 \cdot 40$ & $0 \cdot 38$ & $0 \cdot 24$ \\
\hline \multicolumn{8}{|c|}{ B. Adults $(N=3326)$} \\
\hline Pityriasis & - & $0 \cdot 13$ & $0 \cdot 00$ & $0 \cdot 29$ & $0 \cdot 28$ & -0.05 & $0 \cdot 39$ \\
\hline Folliculosis & $0 \cdot 13$ & - & $0 \cdot 31$ & $0 \cdot 29$ & $0 \cdot 26$ & $0 \cdot 00$ & $0 \cdot 15$ \\
\hline Cheilosis & 0.00 & $0 \cdot 31$ & - & 0.85 & $0 \cdot 04$ & $0 \cdot 40$ & -0.07 \\
\hline Angular stomatitis & $0 \cdot 29$ & $0 \cdot 29$ & 0.85 & - & $-0 \cdot 04$ & $0 \cdot 13$ & $0 \cdot 32$ \\
\hline Enlarged tongue papillae & $0 \cdot 28$ & $0 \cdot 26$ & $0 \cdot 04$ & $-0 \cdot 04$ & - & $-0 \cdot 04$ & 0.06 \\
\hline Gingivitis & -0.05 & $0 \cdot 00$ & 0.40 & $0 \cdot 13$ & $-0 \cdot 04$ & - & 0.05 \\
\hline Corneal vascularization & $0 \cdot 39$ & $0 \cdot 15$ & $-0 \cdot 07$ & $0 \cdot 32$ & 0.06 & 0.05 & - \\
\hline General factor saturation & $0 \cdot 39$ & $0 \cdot 44$ & 0.66 & $0 \cdot 86$ & $0 \cdot 19$ & $0 \cdot 17$ & $0 \cdot 33$ \\
\hline
\end{tabular}

The next analysis includes also the relationship between nutritional grade and the grading criteria which the clinician takes into account in making his assessment. For this purpose one of us (E.W.A.) made a special examination of 1067 children, and in making it recorded his evaluation of those grading criteria which he normally takes into account but does not record in systematic surveys. These criteria are:

Lethargy.

Poor posture.

Abnormal furrow of the back.
Abnormal texture of mucous membranes.

Subcutaneous oedema.

Poor circulation in the limbs.

Presence of goitre.

The suggestions of the Board of Education (1934) for assessing nutrition are here relevant as the following extract shows:

'The main issue is to estimate the general wellbeing of the child. Such general assessment cannot as a rule be based on any single criterion such as any ratio of age, sex, height and weight, but should have regard to other data derived from clinical 
observation; for example the general appearance, facies, carriage, posture; the condition of the mucous membranes; the tone and functioning of the muscular system; and the amount of subcutaneous fat. An alert cheerful child, with bright eyes and a good colour, may usually be accepted as well-nourished without demur. On the other hand, a child who appears dull, listless and tired, who has a muddy complexion or stands slackly, is at once under suspicion, and should be further examined.'

The correlations between some of these criteria and the nutritional grade are shown in Table $3 \mathbf{A}$, and for comparison some of the clinical signs are also included in the table. As before, the only reason for excluding any clinical sign or grading criterion was that the incidence was too low for analysis.

The figures show a high degree of correlation between muscular development, diminished hand grip, amount of subcutaneous fat, and the other grading criteria; and as before, very little correlation for the clinical signs, pityriasis, folliculosis, etc.

It is clear from the analysis that the grading criteria are the main elements in the diagnosis of regard the pooled results of all the criteria as indicative of the general state of nutrition the saturations show us how closely each criterion reflects this general condition. As before the clinical signs, gingivitis, etc., show little relation to each other, and they tend to occur in isolation, whereas the grading criteria (posture, etc.) occur frequently in combination. It is therefore clear that the grading criteria singly and collectively are indicative of the nutritional state as at present understood by the clinician. The contributory variance for the grading criteria is $59 \%$, which means that $59 \%$ of the variance of the general factor can be accounted for in terms of the defects observed. The corresponding figure for the clinical signs in children is $31 \%$. It should not be inferred, however, that these clinical signs are necessarily without value as a means of determining the nutritional state. For example, they may be the first indications of deficiencies of separate nutrients, and as such might give a forewarning of subsequent effects on the general health. To determine this one would have to relate the presence of these signs with

Table 3A. Correlation of clinical signs, and grading criteria, with nutritional assessment

\begin{tabular}{ccccccccccc} 
& & & & & & & \multicolumn{3}{c}{ Diminished } \\
Pityriasis & Folli- & culosis & Gingivitis & posture & the back & ment & grip & sub- & Mucous \\
0.11 & -0.04 & 0.18 & 0.66 & 0.62 & 0.96 & 0.75 & 0.97 & 0.72 & 0.69
\end{tabular}

nutritional grade. This is made still clearer by the correlation between the sum of these criteria and the nutritional assessment which was as high as 0.96 . It may be inferred, then, that whereas individuals of a poor grade of nutrition would be no more likely to have gingivitis or folliculosis than those of a good grade of nutrition, they would be more likely to show, for example, poor posture, poor muscular development and muscular tone than those classified as of good nutrition.

In Table $3 \mathrm{~B}$ are shown the tetrachoric correlations between four clinical signs (gingivitis, etc.) and seven grading criteria (lethargy, etc.).

From inspection we see at once that there is no factor common to the table as a whole on account of the presence of the clinical signs, consequently a factor analysis has only been undertaken for the grading criteria. These latter are analysed in Table $3 \mathrm{C}$, and the general factor saturations are given at the foot of the table. These tell us how far a grading based on any one criterion would compare with the results which would be obtained by using a combination of all the criteria for the assessment.* If we

* In referring to any combination of signs to afford a nutritional assessment standardized measures are implied. the clinical assessment made at a later date when the general effects had had time to develop.

\section{SUMMARY}

The findings of clinical nutrition surveys of 3351 children aged 8-15 years and of 3326 adults, of both sexes, were analysed statistically to ascertain the relationship existing between nutritional grade (good, fair and poor) and the incidence of a variety of clinical signs (pityriasis, folliculosis, gingivitis, etc.) observed at the time of the medical examination but not taken into account in grading the subjects according to their state of nutrition.

The analysis showed negligible correlations between the clinical signs singly and collectively and the clinician's nutritional grade. Further, when we compared the incidence of each clinical sign and the nutritional state as a combination of all the clinical signs (i.e. the general nutritional factor), there was negligible agreement as shown by the low general factor saturation coefficients, thus suggesting that the presence of these signs is not a dependable expression of the general state of nutrition.

A special clinical survey of 1067 children was carried out to provide data which would throw light on the relationship between the criteria 


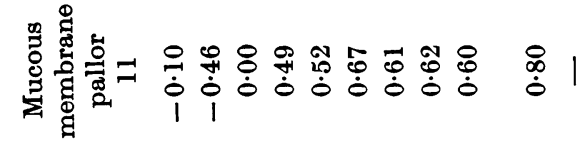

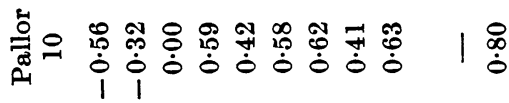

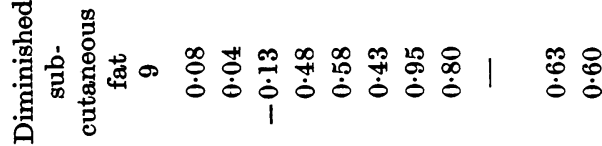

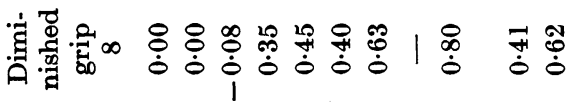
要䓪

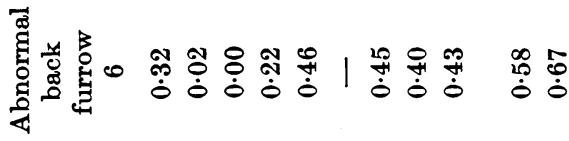

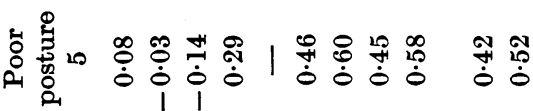

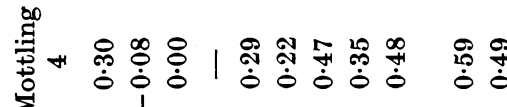

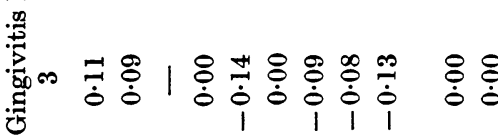

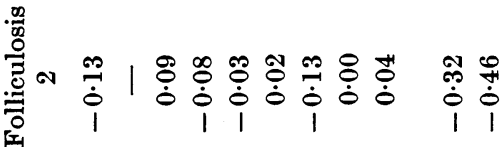
兽-

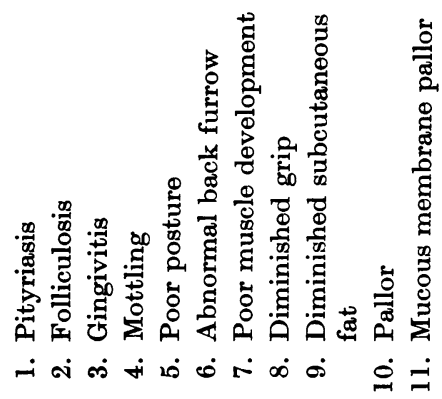

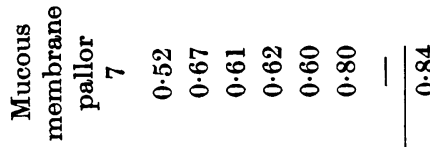

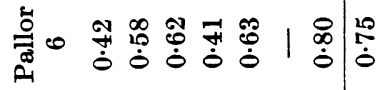

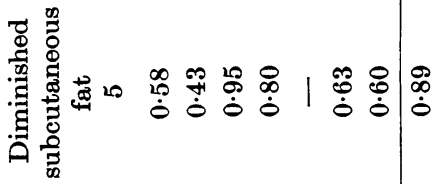

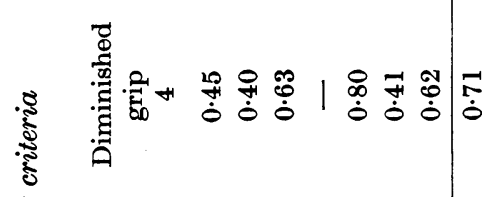

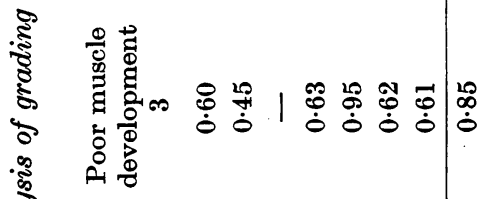

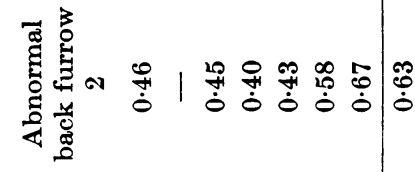

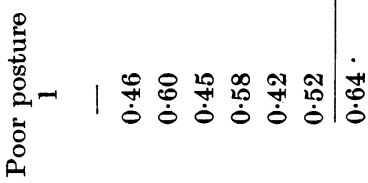

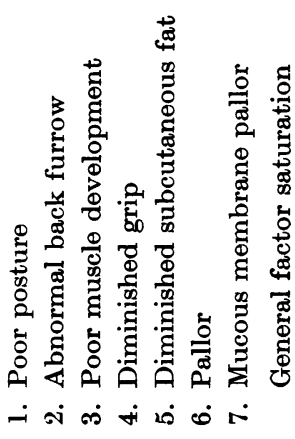


(posture, muscular development, etc.) which the clinician consciously takes into account but does not as a rule record in deciding the nutritional grade, and the nutritional grade itself. The grading criteria in the survey were separately assessed and recorded and so also were the usual clinical signs (pityriasis, gingivitis, etc.).

For the grading criteria there was a high degree of correlation between each one and the nutritional grade and also between each one and the combined pool of all the criteria. The clinical signs showed only negligible correlations with each other, with the nutritional grade or with any of the grading criteria.

It would seem, therefore, that nutritional assessment as at present understood is determined mainly by the value placed on the grading criteria (posture, muscular development, etc.), and to a negligible extent or not at all by the presence or absence of clinical signs (pityriasis, folliculosis, gingivitis, etc.).

\section{REFERENCES}

Hammond, W. H. (1944). J. Hyg., Camb., 43, 395.

Magee, H. E. (1944). Mon. Bull. Minist. Hlth, 3, 146.

(MS. received for publication 18. III. 46.-Ed.) 